\title{
D-1 and D-2 Agonists in Parkinson's Disease
}

\author{
Abraham N. Lieberman, Menek Goldstein, Govindan Gopinathan \\ and Andreas Neophytides
}

\begin{abstract}
We have evaluated 5 DA agonists-bromocriptine, lergotrile, lisuride, pergolide, and mesulergine in studies encompassing 278 patients with advanced PD. In most of our patients the DA agonist was added to levodopa. Most of our patients were no longer satisfactorily responding to levodopa. Previous attempts at managing these patients by changing the dose of levodopa (increasing or decreasing it), the treatment schedule, or the ratio of levodopa to carbidopa or by temporarily discontinuing levodopa [drug holiday] were unsuccessful. The majority of our patients had diurnal fluctuations in performance, either "wearing off" or "on-off" phenomena. The addition of a DA agonist resulted in a decrease in parkinsonian disability in most patients and a decrease in the severity of the diurnal fluctuations in performance. Improvement in many patients was maintained for at least 2 years. Adverse effects included mental changes, dyskinesias, orthostatic hypotension, and nausea. All of the adverse effects were reversible when the agonist was decreased or discontinued. As a group the agonists behaved similarly but individual patients often responded better to one agonist than another. The main role of agonists is in combination with levodopa in the treatment of patients with early PD who have not yet developed dyskinesias or diurnal fluctuations in performance.
\end{abstract}

RÉSUMÉ: Les agonistes des récepteurs D-1 et D-2 dans la maladie de Parkinson. Nous avons évalué 5 agonistes dopaminergiques - la bromocriptine, le lergotrile, le lisuride, le pergolide et la mésulergine par des études comprenant: 278 patients souffrant d'une maladie de Parkinson avancée. Chez la plupart de nos patients, l'agoniste dopaminergique était ajouté à la lévodopa. La plupart de nos patients ne répondaient plus de façon satisfaisante à la lévodopa. Toutes les tentatives antérieures de contrôler la symptomatologie de ces patients en changeant la dose de lévodopa (augmentation ou diminution), l'horaire de la prise du médicament, la proportion de lévodopa par rapport à la carbidopa ou en retirant temporairement la lévodopa [drug holiday] se sont soldées par un échec. La majorité de nos patients avaient des fluctuations dans la performance, du type "wearing off" ou épuisement ou du type "on-off". L'addition d'un agoniste dopaminergique a diminué l'invalidité due à la maladie de Parkinson chez la plupart des patients et a diminué la sévérité des fluctuations diurnes dans la performance. L'amélioration chez plusieurs patients s'est maintenue pendant au moins 2 ans. Parmi les effets secondaires, on note les modifications de l'état mental, les dyskinésies, l'hypotension orthostatique et les nausées. Tous les effets secondaires étaient réversibles lorsque la posologie de l'agoniste était diminuée ou qu'il était cessé. L'effet de tous les agonistes était semblable, mais certains patients répondaient mieux à un agoniste qu'à un autre. Le rôle principal des agonistes est dans la thérapie combinée avec la lévodopa chez les patients qui sont au début de leur maladie de Parkinson et qui n'ont pas encore développé de dyskinésies ou de fluctuations diurnes dans la performance.

Can. J. Neurol. Sci. 1987; 14:466-473

The efficacy of levodopa in Parkinson's disease (PD) decreases after several years.' This decreased efficacy has been related both to disease progression and to the effects of levodopa itself. The core disorder in PD is a degeneration of the pigmented neurons in the substantia nigra compacta $\left[\mathrm{SN}_{\mathrm{c}}\right]$ and the locus ceruleus. Paralleling the degeneration in the $\mathrm{SN}_{\mathrm{c}}$ is a loss of dopamine (DA) and DA synthesizing enzymes in the $\mathrm{SN}_{\mathrm{c}}$ and the striatum. ${ }^{2}$ Also the sensitivity of the postsynaptic DA receptors may increase. ${ }^{3}$ Initially, levodopa may compensate for the striatal DA deficiency by increasing the activity of the remaining $\mathrm{SN}_{\mathrm{c}}$ neurons ${ }^{4,5}$ and may promote the formation of dopamine in striatal intraneurons. Eventually, however, these compensatory mechanisms fail. Another problem associated with long-term levodopa therapy is the development of diurnal fluctuations in performance, "wearing-off" and "on-off" phenomena. ${ }^{6.7}$ One hypothesis attributes the fluctuations to inadequate delivery of DA to the postsynaptic striatal receptors. Consequently, several approaches have been taken to augment the delivery of levodopa to the striatum. ${ }^{8.9}$ These approaches include increasing the dose of levodopa, increasing the frequency of levodopa administration, giving parenteral levodopa, ${ }^{10}$ using a controlled release levodopa/carbidopa preparation, changing the levodopa/carbidopa ratio, using a different dopa decarboxylase inhibitor or dietary modification ${ }^{11}$ to eliminate those amino acids that interfere with levodopa absorption. ${ }^{12.13}$ Another hypothesis attributes the decreased response to levodopa and 
the diurnal fluctuations to chronic levodopa administration. ${ }^{14,15}$ Consequently there have been several approaches centering on decreasing or temporarily discontinuing levodopa. ${ }^{16}$ Thus far the benefits of all of these methods of augmenting the delivery or decreasing the dose of levodopa have been limited.

To date, the best results in patients with a decreasing response to levodopa have been achieved with DA agonists, drugs that bypass the degenerating $\mathrm{SN}_{\mathrm{c}}$ neurons and directly stimulate the postsynaptic DA receptors. Even better results are achieved when the DA agonists are used early, before the fluctuations develop. ${ }^{17}$ Because individual DA receptors may be concerned with specific therapeutic actions or adverse effects (in contrast to the less specific action of levodopa) different DA agonists could be directed toward specific $D_{1}$ or $D_{2}$ DA receptors. Additionally some of the DA agonists have a longer duration of action than levodopa, and this itself may result in a smoother response.

The $D_{1}$ DA receptor was initially identified as a DA sensitive adenylate cyclase that was located in the superior cervical ganglion, the retina, and the striatum. Stimulation of the $D_{1} D A$ receptor results in an increased formation of cyclic adenosine monophosphate [AMP]. ${ }^{18}$ There is good agreement between the antipsychotic activity of the phenothiazines and their activity as $D_{1}$ DA receptor blockers. This correlation does not extend to the butyrophenones or sulpiride, which are potent antipsychotic agents but weak $D_{1}$ DA blockers. At the $D_{1} D A$ site DA is a full agonist, apomorphine is a partial agonist [effective mainly at denervated receptors] and bromocriptine is an antagonist. In the striatum $D_{1} D A$ receptors are localized to membranes of intrastriatal gamma amino butyric acid [GABA] neurons.

Stimulation of the $\mathrm{D}_{2}$ DA receptors does not result in increased cyclic AMP. ${ }^{19} \mathrm{D}_{2}$ DA receptors are located in the striatum and in the pituitary. Initially the striatal $D_{2} D A$ receptors were thought to be localized to axons of a descending cortico-striatal tract. ${ }^{20}$ Recent work suggests that these receptors may be on intrastriatal GABA neurons. ${ }^{21}$ All of the major neuroleptic antipsychotic drugs, including the phenothiazines, butyrophenones, and sulpiride, are potent blockers of the $D_{2} D A$ receptors. In addition, DA, apomorphine, and the DA agonists are full agonists at the $D_{2} D A$ receptor.

The $D_{3}$ DA or the presynaptic "autoreceptors" have a high affinity for DA but a low affinity for neuroleptics. In contrast to its action at the $D_{2} D A$ site, bromocriptine is a weak $D_{3} D A$ receptor agonist. 22,23

Several alterations in DA receptor populations have been observed in postmortem brains obtained from parkinsonian patients. ${ }^{24,25}$ Tissue from levodopa untreated parkinsonian patients show a $50 \%$ to $100 \%$ increase in the number of $D_{2} D A$ receptors. Tissue from levodopa treated parkinsonian patients show that the number of $D_{2} D A$ receptors is either normal or low. The increase in the number of $\mathrm{D}_{2} \mathrm{DA}$ receptors in untreated patients may reflect denervation supersensitivity or "up regulation" of the receptors. When brain DA levels are brought closer to normal by treatment then "down regulation" may occur. If the number of receptors is decreased as a consequence of the disease rather than as a consequence of levodopa treatment then the patients may not respond at all to treatment with levodopa or DA agonists. Such unresponsive patients suffer from a more complex problem than just a striatal DA deficiency.
In these studies it was also demonstrated that although there are changes in the number of the $D_{2}$ DA receptors, the binding affinities of these receptors do not change. In addition the $D_{1}$ DA receptors are unchanged or increased slightly by levodopa treatment. The $\mathrm{D}_{3} \mathrm{DA}$ receptors are decreased by $30 \%$ to $50 \%$. There are inherent limitations in understanding the mechanism of action of levodopa and the DA agonists from these studies. Further understanding of the action of levodopa and the DA agonists has come from studies using animal models of parkinsonism.

The existence of two types of striatal DA receptors with opposite effects on cyclic AMP raises the question as to whether stimulation of the $D_{1}$ DA or the $D_{2}$ DA receptor or both is responsible for antiparkinsonian activity. Thus while recent studies indicate a 92 kilodalton (KDA) peptide may represent the binding site subunit of both receptors, biochemical, physiological and behavioral studies with newly developed selective $D_{1}$ and $D_{2}$ DA agonists and antagonists indicate that there is a complex interaction between both receptors. ${ }^{22.23 .26 .27 .28}$ For example the selective $D_{1}$ DA agonist, SKF 38393 enhances cyclic AMP formation in striatal slices while the selective $D_{2}$ DA agonist, LY 141865 inhibits the SKF 38393 increased cyclic AMP formation. Neither the D, DA agonist, SKF 38393 nor the $\mathrm{D}_{2}$ DA agonist LY 141865 restores locomotor activity in reserpinized mice, but the combined administration of these two drugs does. Further, the selective $\mathrm{D}_{2}$ DA agonist LY 141865 prevents the catalepsy that is induced by the selective $D_{1} D A$ antagonist SCH 23390 while the selective $D_{1}$ DA agonist blocks the stereotyped behavior that is induced by $D_{2} D A$ agonists. Based on studies with these selective DA agonists and antagonists in animals and the available clinical data, it is not yet possible to conclude whether stimulation of $D_{1} D A, D_{2} D A$, or both receptors is the most effective. Thus, dopamine (formed from levodopa) and pergolide stimulate both the $D_{1}$ and $D_{2} D A$ receptors, while bromocriptine, lergotrile, lisuride, or mesulergine stimulate only the $\mathrm{D}_{2} \mathrm{DA}$ receptors, None of the available DA agonists, when used alone, is as effective as levodopa. However, several studies indicate that the DA agonists, when given in combination with levodopa, are more effective than levodopa alone. ${ }^{29}$ The increased efficacy of dopamine agonists, when used in combination with levodopa, might be a result of activation of both the $D_{1}$ and the $D_{2}$ DA receptors.

Recently, a mechanism was proposed which could explain the increased efficacy of one DA agonist, bromocriptine in combination with levodopa. ${ }^{30}$ In animal studies, activity of bromocriptine is enhanced by the presence of DA within the nigrostriatal synapses. If $\mathrm{DA}$ is not present (e.g. in animals treated with reserpine or a-methyl p-tyrosine) bromocriptine will not produce those behaviors associated with stimulation of the postsynaptic DA receptors. In vitro studies with striatal DA receptors reveal differences in the way the agonists interact with the DA receptor. Dopamine and some DA agonists induce a conformational change at the receptor which leads to the conversion of the receptor from a low to a high affinity state, resulting in the formation of a ternary complex between agonist, a receptor binding protein and a coupling nucleotide. Bromocriptine does not differentiate between the low and the high affinity states of the DA receptor and is unable to form the ternary complex which mediates DA agonist activity. It is postulated that only in the presence of DA can the ternary complex be formed and that later bromocriptine replaces DA 
in the ternary complex to form a more durable complex. The formation of this more durable complex might explain the enhanced activity of bromocriptine in the presence of levodopa. There is some experimental evidence to support this hypothesis. For example, in primate models of parkinsonism, low doses of bromocriptine have no effect on tremor, but in combination with levodopa, bromocriptine relieves tremor longer than levodopa alone. These studies support the idea that the combination of low doses of bromocriptine with levodopa is valuable in PD and they are in agreement with results from a recent double-blind study. ${ }^{25}$

Recent approaches in developing DA agonists are based on the findings that some agonists, called partial agonists, selectively stimulate presynaptic and supersensitive postsynaptic, but not normosensitive postsynaptic, DA receptors. ${ }^{22}$ Since the denervation of the nigrostriatal DA neurons in PD results in the development of supersensitive postsynaptic DA receptors, it has been assumed that partial DA agonists such as ciladopa, terguride, BHT 920 and EMD 23448 may be effective antiParkinson drugs. It has also been assumed that because partial DA agonists do not stimulate normosensitive postsynaptic DA receptors they will produce fewer side effects. Preclinical and clinical studies with partial DA agonists suggest that these compounds do have anti-parkinsonian activity with fewer side effects such as dyskinesias. To explain the mechanisms underlying the selectivity of these partial DA agonists in stimulating the supersensitive postsynaptic DA receptors, it has been suggested that the supersensitive postsynaptic DA receptors may be coupled differently to the agonists than the normosensitive DA receptors.

The recent findings that a large receptor reserve exists at the presynaptic DA receptors that control DA synthesis offers another explanation for the activity of the partial DA agonists. ${ }^{31}$ It is known that a large receptor reserve may produce an increase in the maximal response for a partial agonist, while in its absence, the response to the partial agonist is small. Thus, partial DA agonists such as ciladopa, EMD 23448 or 3-PPP exert different DA agonistic activity at receptor sites with different receptor reserves. If supersensitive post-synaptic receptors like presynaptic DA receptors have a large receptor reserve, while normosensitive postsynaptic receptors do not, then the selective stimulation of the presynaptic and supersensitive postsynaptic receptors, could be due to the difference in their receptor reserve population.

The effects of DA $D_{1}$ and $D_{2}$ agonists have also been studied using [14 ] 2-deoxyglucose (2 DG) autoradiography in rats with unilateral $\mathbf{S N}_{\mathrm{c}}$ lesions. ${ }^{32.33}$ In these rats the administration of the selective D, DA agonist SKF 38393 results in contralateral turning and increased 2 DG utilization in the ipsilateral entopeduncular nucleus [the rodent homologue of the primate medial pallidum] and in the $\mathrm{SN}$ pars reticulata $\left[\mathrm{SN}_{\mathrm{R}}\right]$. In these rats the administration of levodopa or of the selective $\mathrm{D}_{2}$ agonist LY 171555 also results in contralateral turning but with a bilateral increase in 2 DG utilization in the entopeduncular nuclei and a mild increase in $2 \mathrm{DG}$ utilization in the contralateral $S N_{R}$. These results suggest that the $D_{1}$ and $D_{2}$ agonists may mediate rotation via anatomically distinct striatal efferent pathways and that similar behavior [contralateral turning] may be associated with different biochemical changes. ${ }^{34,35}$

\section{Bromocriptine}

Bromocriptine $\mathrm{a}_{2} \mathrm{DA}$ agonist was the first $\mathrm{DA}$ agonist to be successfully introduced into clinical practice ${ }^{36}$ Our experience with bromocriptine spans 12 years. Initially bromocriptine was used in high doses [more than $30 \mathrm{mg} / \mathrm{day}$ ] in patients with advanced PD, dyskinesias and diurnal fluctuations in performance.$^{37}$ While these patients benefitted from the combination of high dose bromocriptine and levodopa, adverse effects were frequent and limited treatment. In retrospect it is not clear that this was the best way to use bromocriptine but, rather, as recent studies have shown, bromocriptine should be introduced early into the treatment of PD before patients develop dyskinesias or diurnal fluctuations in performance.

In our first large study we administered bromocriptine to 66 patients with advanced PD and increasing disability despite optimal levodopa treatment. ${ }^{38}$ Patients were assessed using a PD Disability Scale on which 0 represents no disability and $100 \%$ maximum disability. ${ }^{39}$ Patients were also staged using the Hoehn and Yahr Scale. Diurnal fluctuations in performance were evaluated by examining patients during both "on" and "off" periods and by asking patients to keep a daily log of the number of hours they were "on". Significant improvement in rigidity, tremor, bradykinesia, postural stability, and gait occurred in 45 patients. The frequency of diurnal fluctuations in performance decreased in 19 of 27 patients. The mean daily dose of bromocriptine was $47 \mathrm{mg}$. This allowed the dose of levodopa to be reduced by $10 \%$. Bromocriptine was discontinued in 29 of the 66 patients because of adverse effects, including mental changes ( 14 patients) and increased dyskinesias ( 9 patients). All of these adverse effects were reversible upon decreasing or stopping bromocriptine.

In a follow-up study of 28 of these patients who were treated with bromocriptine for at least two years (mean duration, 2.8 years; range, two to five years) bromocriptine at a mean dose of $56 \mathrm{mg}$ resulted in improvement in $21(75 \%)$ of the patients. ${ }^{40}$ Sixteen of these patients maintained some of their original improvement after 2 years. During the study, periodic readjustments of the ratio of bromocriptine to levodopa were required.

\section{Lergotrile}

At the time we began studying bromocriptine, we also began studying lergotrile, a semisynthetic ergot alkaloid and $D_{2} D A$ agonist. In our first study with lergotrile, we treated 13 patients, including two patients who had never been treated with levodopa ${ }^{41}$ Lergotrile in doses of up to $20 \mathrm{mg} /$ day resulted in improvement in five patients, including the two previously untreated patients. As predicted by our animal studies, dyskinesias were minimal. In our large study, lergotrile was administered to 53 patients with advanced PD who were experiencing increasing disability despite optimal levodopa treatment. ${ }^{42}$ The 39 patients who were able to tolerate at least $20 \mathrm{mg} /$ day of lergotrile showed significant improvement in rigidity, tremor, bradykinesia, postural stability, and gait. Dyskinesias did not increase. Among these 39 patients there were 23 who had diurnal fluctuations in performance. In 13 of these patients the fluctuations decreased. The mean daily dose of lergotrile was $49 \mathrm{mg} / \mathrm{day}$. The dose of levodopa was reduced by $10 \%$. Lergotrile was discontinued in 33 of the 53 patients because of adverse effects, which included mental changes (12 patients), hepatotoxicity (11 patients), and orthostatic hypotension (5 
patients). Although lergotrile had a definite antiparkinson effect, the incidence of adverse effects, particularly hepatotoxicity, resulted in the cessation of clinical studies with the drug.

Bromocriptine and lergotrile differed principally with regard to adverse effects. Both drugs produced mental changes; bromocriptine and levodopa increased dyskinesias, whereas lergotrile and levodopa did not; lergotrile but not bromocriptine resulted in hepatotoxicity. Although the antiparkinsonian effects of bromocriptine and lergotrile were comparable, differences in individual patient response were apparent. Some patients improved more with bromocriptine, whereas others improved more with lergotrile. ${ }^{43}$

\section{Lisuride}

We next evaluated lisuride, a semisynthetic ergot alkaloid and $D_{2}$ DA agonist that is more potent on a milligram per milligram basis than bromocriptine or lergotrile. Lisuride is also a serotonin agonist. In our first study we replaced levodopa with lisuride in 10 patients with PD whose response to levodopa had decreased. ${ }^{44}$ Five of these patients experienced improvement on lisuride alone. Although this improvement lasted several months eventually the patients needed a combination of lisuride and levodopa. The mean dose of lisuride was $3.6 \mathrm{mg} /$ day (range, 1.6 to $5.0 \mathrm{mg}$ ).

Eventually we treated 63 advanced PD patients with lisuride. ${ }^{45}$ This group included 40 patients with diurnal fluctuations in performance. Lisuride, combined with levodopa, resulted in a significant decrease in disability for the group as a whole. The number of hours during which patients were "on" increased significantly in the 40 patients with diurnal fluctuations. Adverse effects necessitated the discontinuation of lisuride in 26 patients. These adverse effects included an organic confusional syndrome (15 patients) and increased dyskinesias (5 patients). All adverse effects disappeared within several days after decreasing or stopping lisuride.

Lisuride was compared with bromocriptine in 25 patients whose response to levodopa had decreased ${ }^{46}$ Nineteen of these patients had diurnal fluctuations. At the time bromocriptine was added to levodopa, the mean age of the patients was 62.7 years and the mean disease duration was 8.9 years on bromocriptine and levodopa. Disability in these patients decreased by $34 \%$ during "on" periods and by $20 \%$ during "off" periods. The number of hours during which the patients were "on" increased from 9.6 to 12.8 hours. All of these changes were significant. Adverse effects necessitated the discontinuation of bromocriptine in 11 patients. The mean dose of bromocriptine was $55 \mathrm{mg}$ (range, 20 to $100 \mathrm{mg}$ ). At the time lisuride was added to levodopa, the patients were older (65.4 years), had had the disease longer ( 11.4 years), and were more disabled. Nonetheless, disability in these patients decreased by $33 \%$ during "on" periods and by $17 \%$ during "off" periods, and the number of hours during which the patients were "on" increased from 3.9 to 8.9 hours. All of these changes were significant. The mean dose of lisuride was $2.8 \mathrm{mg}$. Lisuride was discontinued in eight patients because of adverse effects. Both bromocriptine and lisuride are useful in managing patients with advanced disease whose response to levodopa has diminished. Individual differences in responses were apparent between the two drugs, with some patients responding better to one agent than the other.

\section{Pergolide}

We next evaluated pergolide, a semisynthetic ergot alkaloid and $D_{1}$ and $D_{2} D A$ agonist. ${ }^{26.47}$ Pergolide like lisuride, is more potent on a milligram per milligram basis than bromocriptine or lergotrile. Pergolide is longer acting than bromocriptine, lergotrile or lisuride. In our first study, pergolide was evaluated in 13 patients with advanced disease and diurnal fluctations in performance whose response to levodopa had decreased. ${ }^{48}$ Among the nine patients who completed the trial, pergolide alone (two patients) or combined with levodopa (seven patients) had a marked antiparkinsonian effect. The mean daily dose of pergolide was $2.4 \mathrm{mg}$ (range, 2 to $5 \mathrm{mg}$.). Eventually we administered pergolide to 56 patients with advanced disease who were no longer satisfactorily responding to levodopa ${ }^{49}$ This group included 45 patients with diurnal fluctuations in performance. Pergolide, combined with levodopa, resulted in a $44 \%$ decrease in disability during "on" periods, a $15 \%$ decrease in disability during "off" periods, and a $148 \%$ increase in the number of hours during which the patients were on (from $4.6 \pm 0.3$ hours to 11.4 \pm 0.6 hours). All of these changes were significant. The mean dose of pergolide was $2.5 \mathrm{mg}$, and the mean duration of the study was 13 months. Maximum improvement occurred within two months, and began to decline after six months. Adverse effects necessitating the discontinuation of pergolide included an organic confusional syndrome (6 patients), and dyskinesias ( 4 patients). Nine patients discontinued pergolide because of a lack of or a declining effect.

The long-term effects of pergolide combined with levodopa were studied in 17 patients, including 15 patients with diurnal fluctations in performance who had been receiving pergolide for at least two years. ${ }^{50}$ The mean duration of the study was 27.8 months (range, 24 to 38 months). All 17 patients had initially improved when pergolide was added to levodopa, but the improvement decreased in time. Decreased receptor sensitization, "down regulation", secondary to prolonged stimulation of the receptors by a DA agonist may account, in part, for the decreased efficacy in time of all of the agonists including levodopa.

We compared pergolide with bromocriptine in 25 levodopatreated patients in whom the response to levodopa had decreased. ${ }^{51}$ All 25 patients had diurnal fluctuations in performance. At the time bromocriptine was added to levodopa, the mean age of these patients was 61.8 , the duration of the disease was 9 years, and the duration of levodopa treatment was 6.1 years. For the group as a whole, disability during "on" periods decreased by $36 \%$, disability during "off" periods decreased by $25 \%$, and the number of hours during which the patients were "on" increased by $62 \%$. All of these changes were significant. Bromocriptine had to be discontinued in 9 patients. The mean dose of bromocriptine was $50 \mathrm{mg}$ (range, 10 to $100 \mathrm{mg}$.) and the mean duration of treatment was 23 months (range, 2 to 65 months). At the time that pergolide was added to levodopa, these patients were older ( 65.5 years), the duration of disease was longer (12.7 years) and disability was greater. For the group as a whole, disability during "on" periods decreased by $40 \%$, disability during "off" periods decreased by $21 \%$, and the number of hours during which the patients were "on" decreased by $24 \%$. The mean dose of pergolide was $2.1 \mathrm{mg}$. Pergolide was discontinued in 8 patients because of side effects. In this retrospective study, pergolide was more useful than bromocriptine because of its efficacy at a more advanced stage of the disease. However in a prospective study comparing 
bromocriptine and pergolide no differences were found between the two drugs. ${ }^{52}$

We compared lisuride with pergolide in 25 patients with advanced disease whose response to levodopa had decreased. This study included 16 patients with diurnal fluctuations in performance. ${ }^{53}$ When added to levodopa, both lisuride and pergolide resulted in a significant decrease in disability during both "on" and "off" periods. The increase in the number of hours during which the patients were "on" was greater in the pergolide-treated patients.

\section{Mesulergine}

We also studied mesulergine, an alpha amino ergolene and $D_{2}$ DA agonist, in 40 patients. ${ }^{54}$ In 20 patients with advanced disease, a declining response to levodopa, dyskinesias and diurnal fluctuations, mesulergine was added to a fixed dose of levodopa. The maximum dose of mesulergine was $20 \mathrm{mg} / \mathrm{day}$. A double-blind randomization to active drug or placebo was performed at the end of the study. Eleven of the 20 patients (55\%) benefitted from mesulergine with a decrease in their disability, no increase in their dyskinesias, and a decrease in their diurnal fluctuations. In another 20 patients, who had less advanced disease, mesulergine was substituted for levodopa. The maximum dose of mesulergine was also $20 \mathrm{mg} /$ day. In this group, no double-blind randomization to active drug or placebo was performed at the end of the study. Reduction in dose of levodopa was the measure of efficacy. In this group of patients, the dose of levodopa was reduced by $64 \%$. Levodopa was completely replaced by mesulergine in 5 patients. Dyskinesias and diurnal fluctuations which were present in these patients on their entry into the study, were reduced by the substitution of mesulergine for levodopa.

Adverse reactions with mesulergine were minimal and were similar to those associated with the other DA agonists. Although mesulergine had significant antiparkinson activity, studies with the drug have been discontinued because of the occurrence of microscopic Leydig cell tumors in some rats after long-term treatment (at least two years). The studies with mesulergine were significant in demonstrating that a drug can have antiparkinson activity yet induce few dyskinesias.

Our experience with the five DA agonists is summarized in Tables 1 - 5. Pretreatment data for the patients studied are presented in Table 1, and information regarding previous levodopa therapy in these patients is shown in Table 2. Table 3 summarizes the results. All five DA agonists studied produced significant $(P \leqslant 0.01)$ improvement. The percentage of patients who improved by at least one stage ranged from $39 \%$ to $80 \%$. Table 4 presents the results of treatment with the DA agonists in patients with diurnal fluctuations. The adverse effects that resulted in the discontinuation of the DA agonist-therapy are summarized in Table 5.

\section{Discussion}

All of the DA agonists are useful in treating patients whose response to levodopa has decreased or who are experiencing diurnal fluctuations in performance. More than half of such patients improved on DA agonists. In these patients, the dose

\begin{tabular}{|c|c|c|c|c|c|c|}
\hline \multirow[b]{2}{*}{ Number of Patients } & \multicolumn{6}{|c|}{ Dopamine Agonist } \\
\hline & $\begin{array}{c}\text { Bromocriptine }^{12} \\
(N=66)\end{array}$ & $\begin{array}{l}\text { Lergotrile }^{16} \\
(\mathrm{~N}=53)\end{array}$ & $\begin{array}{l}\text { Lisuride }^{20} \\
(\mathrm{~N}=63)\end{array}$ & $\begin{array}{l}\text { Pergolide }^{23} \\
(\mathbf{N}=56)\end{array}$ & $\begin{array}{c}\text { Mesulergine }^{30} \\
(\mathrm{~N}=40)\end{array}$ & $\begin{array}{l}\text { Total } \\
278\end{array}$ \\
\hline \multicolumn{7}{|l|}{ Age (yr) } \\
\hline Mean & 62 & 62 & 65 & 63 & 65 & \multirow[t]{2}{*}{63.3} \\
\hline Range & $45-80$ & $45-85$ & $47-82$ & $35-84$ & $50-77$ & \\
\hline Range & $2-48$ & $2-48$ & $3-27$ & $1-31$ & $2-35$ & 11.0 \\
\hline Number $(\%)$ of Patients with dementia & $11(17 \%)$ & $8(15 \%)$ & $11(17 \%)$ & $7(13 \%)$ & $5(12.5 \%)$ & $42(15 \%)$ \\
\hline $\begin{array}{l}\text { Number }(\%) \text { of Patients } \\
\text { with diurnal oscillations }\end{array}$ & $37(56 \%)$ & $23(43 \%)$ & $40(63 \%)$ & $45(80 \%)$ & $26(65 \%)$ & $171(62 \%)$ \\
\hline
\end{tabular}

Table 2: Details of Previous Levodopa Treatment in Patients Participating in Clinical Trials of Dopamine Agonists

\begin{tabular}{|c|c|c|c|c|c|c|}
\hline $\begin{array}{l}\text { Duration of levodopa treatment (yrs) } \\
\text { Mean } \\
\text { Range }\end{array}$ & $\begin{array}{c}5.6 \\
(0-9)\end{array}$ & $\begin{array}{c}6.3 \\
(0-9)\end{array}$ & $\begin{array}{c}8.2 \\
(<1-14)\end{array}$ & $\begin{array}{c}8.9 \\
(<1-13)\end{array}$ & $\begin{array}{l}12.6 \\
(11-14)\end{array}$ & 8.0 \\
\hline $\begin{array}{l}\text { Patients who improved by at least } \\
\text { one stage on levodopa }\end{array}$ & $48(73 \%)$ & $39(74 \%)$ & $53(84 \%)$ & $49(88 \%)$ & $34(85 \%)$ & $223(80 \%)$ \\
\hline $\begin{array}{l}\text { Patients who eventually deteriorated } \\
\text { by at least one stage on levodopa }\end{array}$ & $44(67 \%)$ & $28(53 \%)$ & $30(48 \%)$ & $18(32 \%)$ & $15(38 \%)$ & $135(49 \%)$ \\
\hline
\end{tabular}


of levodopa may be reduced by as much as $25 \%$. The therapeutic response to these agonists usually peaks within six months and then may decline. Approximately $25 \%$ of patients maintain a good response for at least two years.

There are several reasons for the difference in efficacy of the DA agonists in patients with advanced disease: (1) Diurnal fluctuations in performance complicate the evaluation of patients with advanced disease. Unless patients are under 24-hour observation, which is rarely possible, the assessment of efficacy depends upon the evaluation of patients during "on" and "off" periods and by the use of a daily log that is kept by the patient. Unless the physicians and patients are experienced in assessing parkinsonian signs and symptoms, assessments may vary widely. (2) Psychological factors play a prominent role in PD and affect disability scores and diurnal fluctuations. (3) The ergot DA agonists are metabolized by the liver and there are differences in their absorption metabolism and clearance among patients. (4) The effects of dopamine and the DA agonists may be modulated by other neurotransmitters which may coexist in the same neuron with DA. ${ }^{25}$ (5) Some patients with advanced disease may be unable to respond or respond only poorly to treatment.

End-stage disease in the levodopa-DA agonist era differs from end-stage disease in the prelevodopa era. In the prelevodopa era end-stage PD was characterized by marked rigidity, tremor, bradykinesia, and difficulty walking. The "end-stage" patients

Table 3: Response of Patients with Parkinson's Disease to Dopamine Agonists

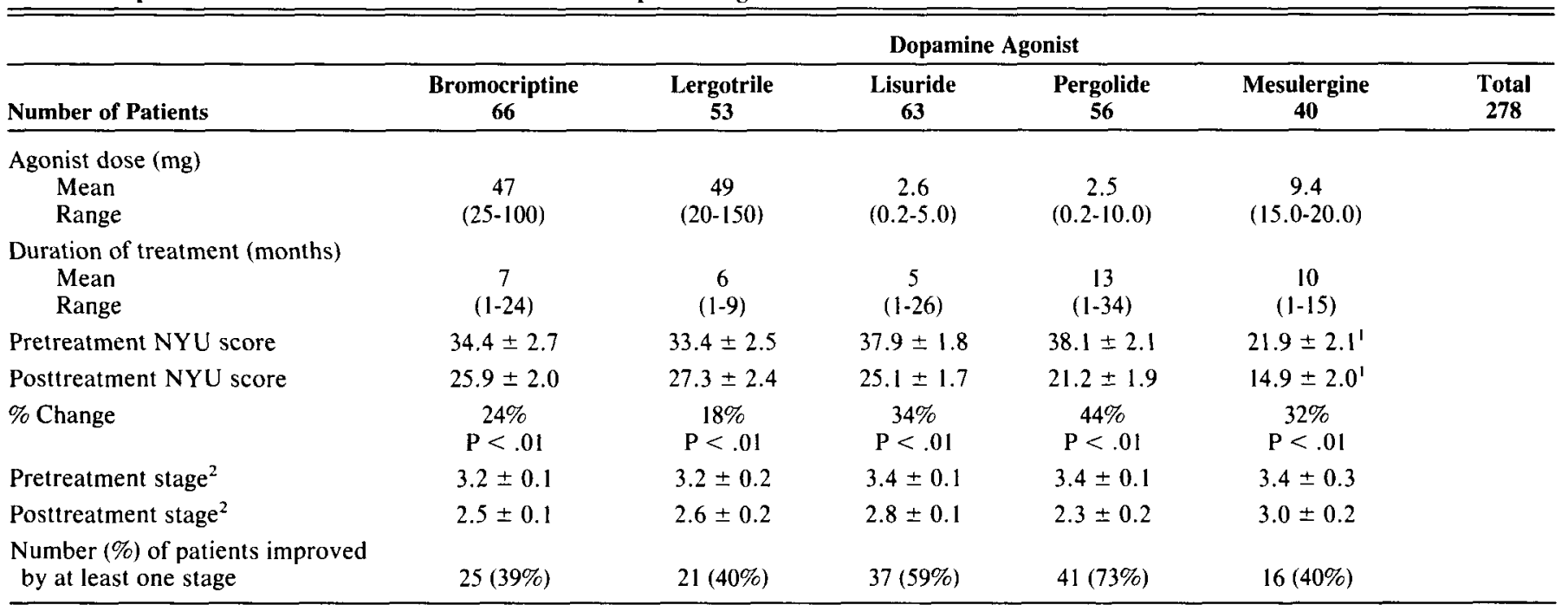

${ }^{1}$ Columbia University Scale

${ }^{2}$ Hoehn and Yahr Scale (patients assessed during "on" periods)

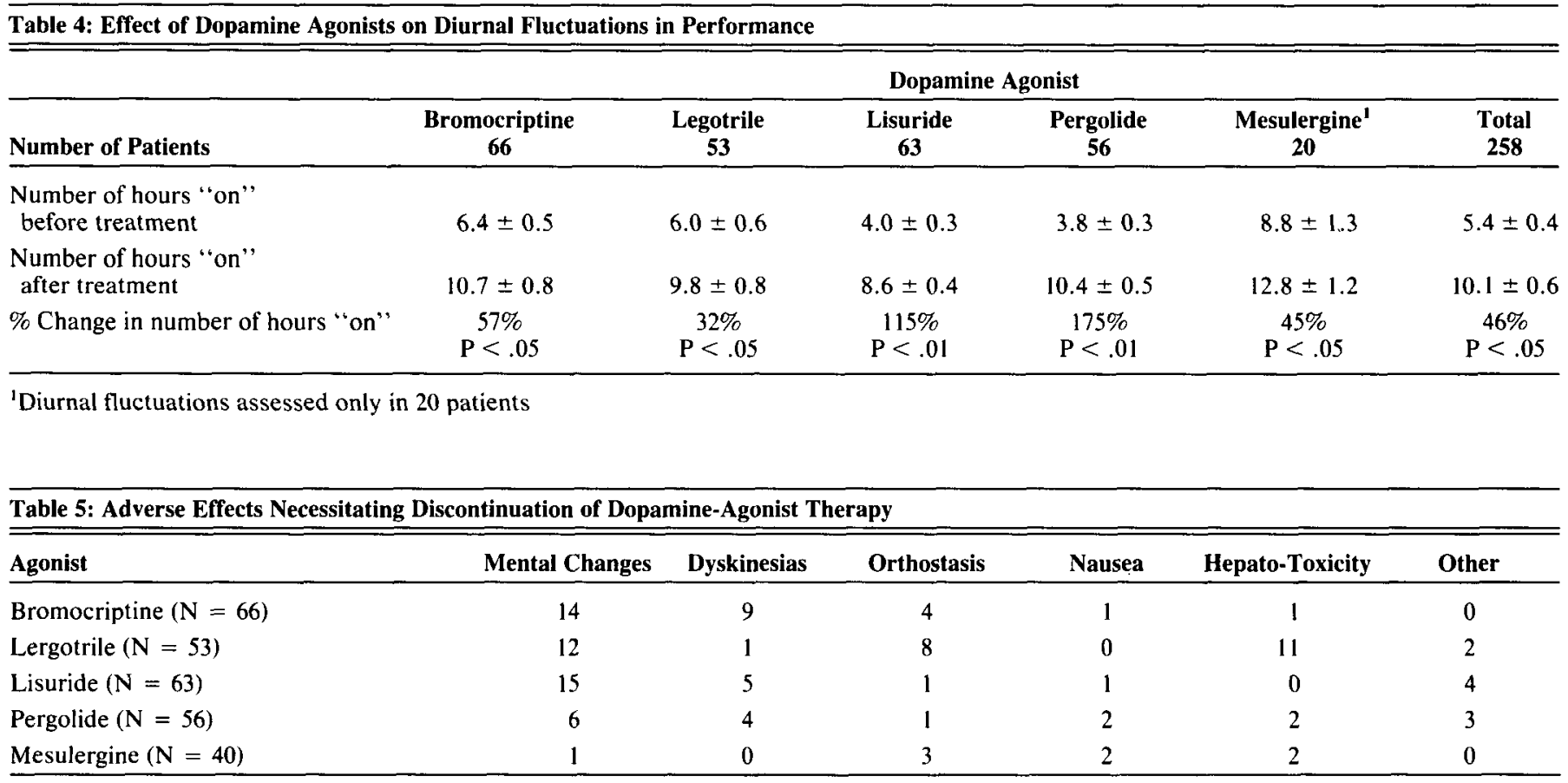


treated with levodopa and DA agonists, however, are not rigid, may not be bradykinetic, and may be able to walk but have marked postural instability and fall easily. Some end-stage patients have violent tremors that shake their beds. Most endstage patients are depressed, and many are demented. Many patients have autonomic insufficiency with dysphagia, and, a few have orhtostatic hypotension. The patients are cachectic and may have recurrent bouts of aspiration pneumonia. The administration of DA agonists, amantadine, anticholinergic agents or tricyclic antidepressants may aggravate the mental changes. In some patients, a low dose of a DA agonist may result in improvement without aggravating the mental changes. These patients seem to respond as though their remaining DA receptors are exquisitely supersensitive.

While the treatment of advanced PD has been improved by the introduction of the DA agonists it is now clear that the main role of these drugs is in the early stage of PD before the patients develop diurnal fluctuations or dyskinesias. Dopamine agonists reduce the dose of levodopa that is needed for the antiparkinson effect. The DA agonists may thus delay the complications of high dose long-term levodopa treatment.

\section{ACKNOWLEDGEMENTS}

The authors wish to thank Linda Chin, R.N. and Kathleen Faridazar, M.A. for their assistance in this study. This paper was supported, in part, by a grant from the Leon Lowenstein Foundation and, in part, by the American Parkinson Disease Association.

\section{REFERENCES}

1. Marsden CD, Parkes JD. Success and problems of long-term levodopa therapy in Parkinson's disease. Lancet 1977; 1: 345-349.

2. Bernheimer J, Birkmayer W. Hornykiewicz O. Brain Dopamine in syndromes of Parkinson and Huntington. J Neurol Sci 1973; 20: 415-455.

3. Ungerstedt U. Post-synaptic supersensitivity after 6-hyrdoxydopamine induced degeneration of the nigrostriatal dopamine system. Acta Physiol Scand 1971; 367(Suppl): 69-93.

4. Agid Y, Javoy F, Glowinski J. Hyperactivity of the remaining neurones after partial destruction of the nigrostriatal dopaminergic system in the rat. Nature 1973: 245: 150-151.

5. Melamed E, Hefti F, Wurtman RJ. Diminished decarboxylation of L-dopa in rat striatum after intrastriatal injections of kainic acid. Neuropharmacology 1980; 19; 409-411.

6. Marsden CD, Parkes JD, Quinn N. Fluctuations of disability in Parkinson's disease - clinical aspects, in Marsden CD, Fahn S (eds.). Movement Disorders. London, Butterworth, 1982, pp 106-128.

7. Muenter MD, Sharpless NS. Tyce GM. Patterns of Dystonia ("I.D.I" and "D.I.D") in response to L-dopa therapy for Parkinson's disease. Mayo Clinic Proc 1977; 52: 165-174.

8. DeJong GJ, Meerwaldt JD. Response variations in the treatment of Parkinson's disease. Neurology 1984; 34: 1507-1509.

9. Spencer SE, Wooten, GF. Altered Pharmacokinetics of L-dopa metabolism in rat striatum deprived of dopaminergic innervation. Neurology 1984; 34: 1105-1108.

10. Quinn N, Parkes JD, Marsden CD. Control of on/off phenomenon by continuous intravenous infusion of levodopa. Neurology 1984; 34: 1131-1136.

11. Lieberman AN, Goldstein M. Gopinathan G. Combined use of benserazide and carbidopa in Parkinson's disease. Neurology 1984; 34: 227-229.

12. Nutt JG, Woodward WR, Hammerstad JP, et al. The "on-off" phenomenon in Parkinson's disease. Relation tolevodopa absorption and transport. New Eng J Med 1984; 310: 483-488.

13. Nutt JG, Woodward WR. Levodopa pharmacokinetics and pharmoacodynamics in fluctuating parkinsonian patients. Neurology $1986 ; 36: 739-744$.
14. Dougan D, Wade D, Mearrick P. Effects of L-dopa metabolites at a dopamine receptor suggest a basis for "on-off' effect in Parkinson's disease. Nature 1975; 254: 70-72.

15. Lesser RP, Fahn S, Snider SP, et al. Analysis of the clinical problems in parkinsonism and the complications of long-term levodopa therapy. Neurology 1979; 29: 1253-1260.

16. Direnfeld LK, Feldman RC, Alexander MP. Is L-dopa drug holiday useful. Neurology 1980; 30: 785-788.

17. Rinne UK. Combined bromocriptine-levodopa therapy early in Parkinson's disease. Neurology 1985; 35: 1196-1198.

18. Kebabian JW, Petzold GL, Greengard P. Dopamine sensitive adenylate cyclase in caudate nucleus of rat brain and its similarity to the dopamine receptor. Proc Natl Acad Sci USA 1972; 69: 2145-2149.

19. Schwarcz R, Fuxe K, Agnati LF. Effects of bromocriptine on $3 \mathrm{H}$-spiroperidol binding sites in rat striatum: Evidence for actions of dopamine receptors not linked to adenylate cyclase. Life Sci 1978; 23: 465-470.

20. Schwarcz R, Creese I, Coyle JT. Dopamine receptors localized on cerebral cortical afferents to rat striatum. Nature 1978; 271: 766-768.

21. Trugman JM, Geary WA, Wooten GF. Localization of $D_{2}$ dopamine receptors to intrinsic striatal neurons by quantitative autoradiography. Nature 1986; 323: 267-269.

22. Rabey JM, Passeltiner P, Markey K. Stimulation of pre and postsynaptic dopamine receptors by an ergoline and by a partial ergoline. Brain Research 1981; 225: 347-356.

23. Goldstein M, Lew JY, Engel J. Dopaminephillic properties of ergot derivatives. In: Fuxe K, Calne DB, eds. Dopaminergic ergot derivatives and motor function. Oxford: Pergamon Press, 1979: 253-260.

24. Reisine TD, Fields JZ, Yamamura HJ. Neurotransmitter receptor alterations in Parkinson's disease. Life Sci 1977; 21: 335-344.

25. Rinne UK, Koskinen V, Lonnberg P. Neurotransmitter receptors in the parkinsonian brain. Parkinson Disease edited by Rinne UK, Klinger M, and Stamm G. Elsevier North Holland BioMedical Press 1980; 93-107.

26. Goldstein M, Lieberman AN, Lew JY. Interaction of pergolide with central dopaminergic receptors. Proc Natl Acad Sci 1980; 77: 3725-3728.

27. Lew JY, Meller E, Goldstein M. Photoaffinity labeling and purification of solubilized $D_{2}$ dopamine receptors. Europ J Pharm 1985; 113: 145-146.

28. Lew JY, Goldstein M. Solubilization and characterization of striatal dopamine receptors. J Neurochem 1984; 42: 1298-1305.

29. Lieberman A, Goldstein M. Bromocriptine in Parkinson Disease. Pharm Reviews 1985; 37: 217-227.

30. Goldstein M, Lieberman A, Meller E. A possible molecular mechanism for the anti-parkinsonian action of bromocriptine in combination with levodopa. Trends in Pharm Sci 1985; 6: 436-437.

31. Meller E, Hellmer, Matyjek E, et al. Receptor reserve at striatal dopamine autoreceptors: Implications for selectivity of dopamine agonists. Europ J of Pharmacology 1986; 123: 311-314.

32. Trugman JM, Wooten GF. The effects of L-dopa on regional cerebral glucose utilization in rats with unilateral lesions of the substantia nigra. Brain Research 1986; 379: 264-274.

33. Bennett JP, Wooten GF. Dopamine Denervation does not alter in vivo $3 \mathrm{H}$ spiperone binding in rat striatum: Implications for external imaging of dopamine receptors in Parkinson's disease. Ann Neurol 1986; 19: 378-383.

34. Herrera, Marschitz M, Ungerstedt U. Evidence that striatal efferents relate to different dopamine receptors. Brain Research 1984; 323: 269-278.

35. Herrera, Marschitz M, Ungerstedt U. Evidence that apomorphine and pergolide induce rotation in rats by different actions on $\mathrm{D}_{1}$ and $D_{2}$ receptor sites. Europ J of Pharm 1984; 98: 165-176.

36. Calne DB, Williams AC, Neophytides A. Long-term treatment of parkinsonism with bromocriptine. Lancet 1978; 1: 735-738.

37. Lieberman A, Kupersmith M, Estey E. The treatment of Parkinson's disease with bromocriptine. New Engl J Med 1976; 295 ; 1400-1404.

38. Lieberman A, Kupersmith M, Gopinathan G. Bromocriptine in Parkinson's disease: Further studies. Neurology 1979; 29:363-369.

39. Lieberman AN, Dziatelowski M, Kupersmith M. The evaluation of Parkinson's disease. Adv Biochem Psychopharmacol 1980; 23: $277-286$ 
40. Lieberman A, Kupersmith M, Neophytides A. Long-term efficacy of bromocriptine in Parkinson's disease. Neurology 1980;30: 518-523.

41. Lieberman A, Miyamoto T, Battista A, et al. Studies on the antiparkinsonian efficacy of lergotrile. Neurology 1975;25: 459-462.

42. Lieberman AN, Gopinathan G, Estey E. Lergotrile in Parkinson's disease: Further studies. Neurology 1979: 29: 267-272.

43. Lieberman AN, Kupersmith M, Gopinathan G. Modification of the "on-off" effect by bromocriptine and lergotrile. In: Fuxe K, Calne DB, eds. Dopaminergic ergot derivatives and motor function. Oxford: Pergamon Press, 1979: 285-295.

44. Lieberman A, Goldstein M, Neophytides A. Lisuride in Parkinson's disease: The efficacy of lisuride compared to levodopa. Neurology 1981; 31: $961-965$.

45. Lieberman A, Goldstein M, Gopinathan G. Further studies with lisuride in Parkinson's disease. Eur Neurol 1983; 22: 119-123.

46. Lieberman A, Gopinathan G, Neophytides A. Bromocriptine and lisuride in Parkinson's disease. Ann Neurol 1983; 13: 44-77.

47. Lemberger L, Crabtree RE. Pharmacological effects in man of a potent long-acting dopamine receptor agonist. Science 1979: 205: 1151-1153.
48. Lieberman A. Goldstein M, Leibowitz M. Treatment of advanced Parkinson's disease with pergolide. Neurology 1981:31:675-682.

49. Lieberman AN, Goldstein M, Gopinathan G. Further studies with pergolide in Parkinson's disease. Neurology 1982:32: 1 181-1184.

50. Lieberman AN, Goldstein M. Leibowitz M. Long-term treatment with pergolide: Decreased efficacy with time. Neurology 1984: 34: $223-226$

51. Lieberman AN, Neophytides A, Leibowitz M. Comparative efficacy of pergolide and bromocriptine in patients with advanced Parkinson's disease. Adv Neurol 1983; 37: 95-108.

52. Lewitt PA, Ward MD, Larsen TA. Comparison of pergolide and bromocriptine therapy in parkinsonism. Neurology 1983: 33: 1009-1014.

53. Lieberman AN. Gopinathan G, Neophytides A. Pergolide and lisuride in advanced Parkinson's disease. Adv Neurol 1983: 40: 503-507.

54. Gopinathan G, Lieberman AN, Pasternack D. Mesulergine in Parkinson's disease. Canad J Neurol Sci (submitted).

55. Hökfelt T, Holets VR Staines W. Coexistence of neuronal messengers - An overview. Prog in Brain Research 1986: 68: 33-70. 